Polymer Journal, Vol. 10, No. 1, pp 1-11 (1978)

\title{
Studies on Formaldehyde Resin. XVI. Hydroxymethylation of Melamine with Formaldehyde in Weakly Acidic Region and without Additional Catalyst
}

\author{
Kenji SAto and Shuichi OuchI \\ Department of Industrial and Engineering Chemistry, Science University \\ of Tokyo, Yamazaki, Noda, Chiba 278, Japan.
}

(Received April 21, 1977)

\begin{abstract}
Early stage hydroxymethylation of melamine with formaldehyde to form monomethylolmelamine in the weakly acidic region of $0<S<1.0$, and in the absence of the catalyst, $S=0(\mathrm{pH}, c a .3-8)$ was investigated kinetically at $40^{\circ} \mathrm{C}$ in aqueous media; here $S$ denotes [hydrochloric acid] $]_{0} /[\text { melamine] }]_{0}$ As a result, the hydroxymethylation rate in the region of $0 \leqq S<1.0$ was found to be dependent on the concentration of the melamine molecule (base species) $\mathrm{MH}$ and its conjugate acid $\mathrm{MH}_{2}{ }^{+}$ in the following manner: rate $=k_{\mathrm{H}_{2} \mathrm{O}}[\mathrm{MH}][\mathrm{HCHO}]+k_{\mathrm{H}}+\left[\mathrm{MH}_{2}+\right][\mathrm{HCHO}]+k_{\mathrm{MH}_{2}+}+\left[\mathrm{MH}_{2}{ }^{+}\right]$ $[\mathrm{MH}][\mathrm{HCHO}]+k_{\mathrm{MH}}[\mathrm{MH}]^{2}[\mathrm{HCHO}]$. In particular, the rate at $S=0$ was represented by rate $=k_{\mathrm{H}_{2} \mathrm{O}}[\mathrm{MH}][\mathrm{HCHO}]+k_{\mathrm{MH}}[\mathrm{MH}]^{2}[\mathrm{HCHO}]$. The values of the rate constants $\left(k_{\mathrm{H}_{2} \mathrm{O}}\right.$, $k_{\mathrm{H}^{+}}, k_{\mathrm{MH}_{2}}+$, and $k_{\mathrm{MH}}$ ) were obtained, and then the relative contributions of these four reactions at $\mathrm{pH}$ 3-8 were made clear in connection with the initial concentration of melamine.
\end{abstract}

KEY WORDS Melamine / Formaldehyde / Hydroxymethylation /

Formaldehyde Resin / Amino Resin / General Base Catalysis /

General Acid Catalysis /

In a preceding paper, ${ }^{1}$ we reported that the kinetic study of hydroxymethylation of melamine with formaldehyde to form monomethylolmelamine in the strongly acidic region of $S=$ $1 \sim 5$ ( $\mathrm{pH} 2.5-0.6)$, where $S$ denotes [hydrochloric acid $]_{0} /[\text { melamine }]_{0}$. The present work summarizes a kinetic study of the early stage hydroxymethylation of melamine in the weakly acidic region of $0<S<1.0$ and in the absence of the catalyst, $S=0(\mathrm{pH}, c a .3-8)$.

Okano and Ogata, ${ }^{2}$ on the basis of their extensive study of the hydroxymethylation of melamine with formaldehyde, reported that hydroxymethylation in the region between the absence of the catalyst and $\mathrm{pH} 4.5$ takes place only by a reaction of melamine molecules with formaldehyde molecules $\left(k_{\mathrm{H}_{2} \mathrm{O}}\right.$-reaction in eq 15$)$; other investigators ${ }^{3}$ have carried out further research by the use of this mechanism for melamine hydroxymethylation. This mechanism was discussed as follows.

Addition of hydrochloric acid to a mixture of melamine and formaldehyde results in the dominant addition reaction of hydrochloric acid to melamine to form the conjugate acid of melamine because the base constant of melamine ${ }^{4}$ is much greater than that of formaldehyde ${ }^{5}(c f$. eq 1 and 2). Consequently, the concentration of melamine molecules at $S=1 / 2(\mathrm{pH} \mathrm{5.0)}$ is one-half of that of melamine molecules at $S=0$. Thus, according to this mechanism, the rate at $S=1 / 2$ should be one-half of that at $S=0$, but our preceding paper $^{1}$ indicated that the hydroxymethylation rate at $S=1 / 2$ is slightly larger than that at $S=0$. Accordingly, this experimental result can not be explained by this mechanism. Therefore, in order to elucidate the mechanism of hydroxymethylation of melamine with formaldehyde in the region of $0 \leqq S<1.0$, a kinetic investigation was made in the present work.

In this paper, [ ] expresses the concentration $\left(\mathrm{mol} l^{-1}\right)$ and []$_{0}$, the initial concentration $\left(\mathrm{mol} l^{-1}\right)$. 


\section{EXPERIMENTAL}

\section{Materials}

Commercially available melamine and paraformaldehyde were purified by the method described in a preceding paper. ${ }^{1}$

\section{Kinetics}

In a thermostat adjusted to the reaction temperature, an appropriate quantity of melamine and sodium perchlorate were dissolved and brought to $1 l$ with distilled water; there also a suitable concentration of formaldehyde was brought to $200 \mathrm{ml}$ with distilled water. These two solutions were mixed, aliquots were taken out at certain intervals, and the amount of unreacted formaldehyde was determined by the sulfite method. ${ }^{2}$ The $\mathrm{pH}$ was measured with a glass electrode $\mathrm{pH}$-meter. The reaction temperature was $40^{\circ} \mathrm{C}$ and ionic strength of the media was adjusted to 0.07 with the above sodium perchlorate. Since the early stage hydroxymethylation was examined in this work, the formation of the methylene linkage would be small, and its effect was neglected in this paper.

\section{RESULTS AND DISCUSSION}

\section{Reaction-Order}

For the hydroxymethylation of melamine with formaldehyde in the strongly acid region of $S>$ 1.0 , a preceding paper ${ }^{1}$ showed that the hydroxymethylation follows the second-order kinetics i.e., $R_{0}=k[\text { melamine }]_{0}[\text { formaldehyde }]_{0}$, where $R_{0}$ is the initial rate.

In the region of $0 \leqq S \leqq 1.0$, the reaction-order was determined.

First, the reaction-order with respect to [formaldehyde] $]_{0}$ was determined. The value of $R_{0}$ was calculated from the initial slope of the plots of formaldehyde consumed and reaction time. Figure 1 shows the plots of $\log R_{0}$ against $\log [\text { formaldehyde }]_{0}$ at constant [melamine $]_{0}$ and $\mathrm{pH}$, giving a linear relation with a slope of 1.0, irrespective of the $\mathrm{pH}$ of the media. It follows first-order kinetics with respect to [formaldehyde] $]_{0}$.

Next, the reaction-order for [melamine] $]_{0}$ was investigated. At constant [formaldehyde], [melamine] $]_{0}$ was varied and $S$ was made constant with hydrochloric acid. (Since the values of $S$ were made constant in each series of Table

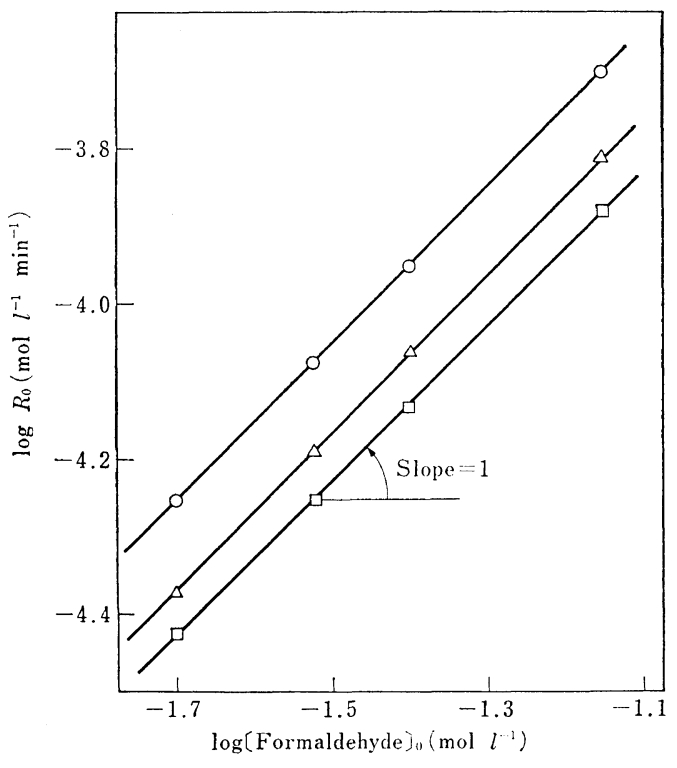

Figure 1. Linear dependence of $\log R_{0}$ on $\log$ [formaldehyde $]_{0}$ at [melamine $]_{0}=0.07 \mathrm{~mol} l^{-1}$ and $40^{\circ} \mathrm{C}$ : $\triangle, 0$ (pH 8.0); $\bigcirc, 0.25$ (pH 5.5); $\square, 0.80$ (pH 4.4) for $S$.

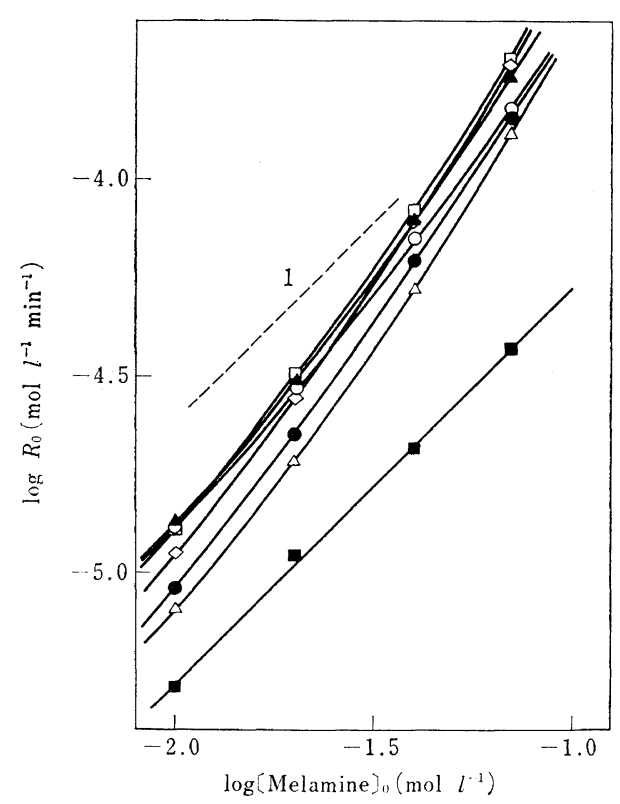

Figure 2. Relationship between $\log R_{0}$ and $\log$ [melamine] $]_{0}$ at [formaldehyde] $0=0.07 \mathrm{~mol} l^{-1}$ and $40^{\circ} \mathrm{C}: \bigcirc, 0 ; \Delta, 0.10 ; \square, 0.25 ; \diamond, 0.50 ; \bigcirc, 0.70$; $\triangle, 0.80 ; \square, 1.0$ for $S$; dotted line, slope. Points refer to Table $I$. 
Hydroxymethylation of Melamine with Formaldehyde

Table I. Dependence of initial rates $\left(R_{0}\right)$ and the second-order rate constants $(k)$ of the hydroxymethylation of melamine on [melamine] $]_{0}$ at $40^{\circ} \mathrm{C}$ and ionic strength of 0.07

\begin{tabular}{|c|c|c|c|c|c|c|}
\hline Run & $\left.\underset{\mathrm{mol} l^{-1}}{[\mathrm{Melamine}}\right]_{0}$ & $\underset{\operatorname{mol} l^{-1}}{\text { [Formalde }}$ & $\begin{array}{c}{[\mathrm{HCl}]_{0} /} \\
{\left[\begin{array}{c}\text { Melamine } \\
(\equiv S)\end{array}\right.}\end{array}$ & $\mathrm{pH}$ & $\begin{array}{c}R_{0} \times 10^{5} \\
\mathrm{~mol} l^{-1} \mathrm{~min}^{-1}\end{array}$ & $\begin{array}{c}k \times 10^{2} \\
l \mathrm{~mol}^{-1} \mathrm{~min}^{-1}\end{array}$ \\
\hline 1 & 0.07 & 0.07 & 0.00 & 8.0 & 15.04 & 3.14 \\
\hline 2 & 0.04 & 0.07 & 0.00 & 7.6 & 7.05 & 2.52 \\
\hline 3 & 0.02 & 0.07 & 0.00 & 7.4 & 2.98 & 2.12 \\
\hline 4 & 0.01 & 0.07 & 0.00 & 7.3 & 1.32 & 1.88 \\
\hline 5 & 0.07 & 0.07 & 0.10 & 5.9 & 18.15 & 3.69 \\
\hline 6 & 0.04 & 0.07 & 0.10 & 5.9 & 7.92 & 2.83 \\
\hline 7 & 0.02 & 0.07 & 0.10 & 5.9 & 3.08 & 2.20 \\
\hline 8 & 0.01 & 0.07 & 0.10 & 5.9 & 1.34 & 1.91 \\
\hline 9 & 0.07 & 0.07 & 0.25 & 5.6 & 19.80 & 4.02 \\
\hline 10 & 0.04 & 0.07 & 0.25 & 5.6 & 8.40 & 2.98 \\
\hline 11 & 0.02 & 0.07 & 0.25 & 5.5 & 3.15 & 2.24 \\
\hline 12 & 0.01 & 0.07 & 0.25 & 5.5 & 1.30 & 1.85 \\
\hline 13 & 0.07 & 0.07 & 0.50 & 5.0 & 19.48 & 3.97 \\
\hline 14 & 0.04 & 0.07 & 050 & 5.0 & 7.80 & 2.78 \\
\hline 15 & 0.02 & 0.07 & 0.50 & 4.9 & 2.79 & 1.99 \\
\hline 16 & 0.01 & 0.07 & 0.50 & 4.9 & 1.12 & 1.59 \\
\hline 17 & 0.07 & 0.07 & 0.70 & 4.6 & 14.35 & 2.90 \\
\hline 18 & 0.04 & 0.07 & 0.70 & 4.6 & 6.20 & 2.21 \\
\hline 19 & 0.02 & 0.07 & 0.70 & 4.6 & 2.24 & 1.61 \\
\hline 20 & 0.01 & 0.07 & 0.70 & 4.6 & 0.91 & 1.30 \\
\hline 21 & 0.07 & 0.07 & 0.80 & 4.5 & 13.14 & 2.64 \\
\hline 22 & 0.04 & 0.07 & 0.80 & 4.4 & 5.28 & 1.90 \\
\hline 23 & 0.02 & 0.07 & 0.80 & 4.4 & 1.94 & 1.39 \\
\hline 24 & 0.01 & 0.07 & 0.80 & 4.4 & 0.82 & 1.15 \\
\hline 25 & 0.07 & 0.07 & 1.0 & 3.1 & 3.75 & 0.77 \\
\hline 26 & 0.04 & 0.07 & 1.0 & 3.1 & 2.08 & 0.74 \\
\hline 27 & 0.02 & 0.07 & 1.0 & 3.1 & 1.10 & 0.77 \\
\hline 28 & 0.01 & 0.07 & 1.0 & 3.2 & 0.51 & 0.72 \\
\hline
\end{tabular}

I, the values of $\mathrm{pH}$ were also kept nearly constant.) Table I summarizes $R_{0}$ and $k$ together with the reaction conditions, where $k$ is the second-order rate constant if $R_{0}=k[\text { melamine }]_{0}$ [formaldehyde] $]_{0}$ were to be assumed. With the use of data in Table $\mathrm{I}, \log R_{0}$ were plotted against $\log [\text { melamine }]_{0}$ as shown in Figure 2 . As is seen from Figure 2, slight upward curvatures with the slope increasing from 1.25 to 1.45 were obtained with increasing [melamine $]_{0}$ at constant $S$ of $0,0.10,0.25,0.50,0.70$, and 0.80 ; but for $S=1.0$, a straight line with a slope of $c a .1 .0$ was obtained and this result is the same as that of the strong acid region of $S>1.0^{1}$. In addition, plots of $R_{0}$ against [melamine] $]_{0}$ are shown in Figure 3, in which a linear dependence of $R_{0}$ on [melamine] was approximately observed at $S=1.0$, whereas the decided upward curvatures were observed in the region of $0 \leqq S<$ $1.0 ; v i z ., R_{0} \propto[\text { melamine }]_{0}{ }^{n}(n>1)$ was, undoubtedly, established in the region of $0 \leqq S<1.0$.

Consideration on the Reaction Mechanism Reported Previously

In the presence of an acid catalyst, the melamine molecules $\mathrm{MH}$ form conjugate acids $\mathrm{MH}_{2}{ }^{+4}$ and also $\mathrm{MH}_{3}{ }^{2+6}$ according to the equilibrium of eq 1 , while the formaldehyde molecules form methylol cations according to eq 2 . Clearly, eq 1 and 2 are both fast pre-equilibria, and $K_{1}, K_{2}$, and $K_{3}$ are the respective equilibrium constants. 


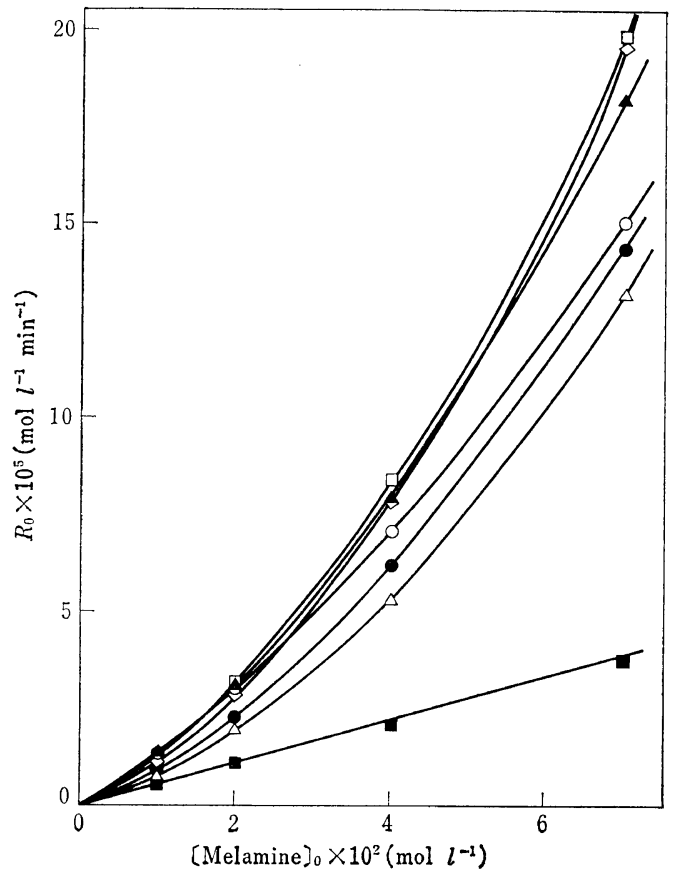

Figure 3. Relationship between $R_{0}$ and [melamine $]_{0}$ at [formaldehyde] $]_{0}=0.07 \mathrm{~mol}^{-1}$ and $40^{\circ} \mathrm{C}$ : $\bigcirc, 0 ; \Delta, 0.10 ; \square, 0.25 ; \diamond, 0.50 ; \bigcirc, 0.70 ; \triangle, 0.80$; 口, 1.0 for $S$.

$$
\mathrm{MH}+\mathrm{H}^{+} \stackrel{K_{1}}{\longleftrightarrow} \mathrm{MH}_{2}^{+}, \quad \mathrm{MH}_{2}^{+}+\mathrm{H}^{+} \stackrel{K_{2}}{\longleftrightarrow} \mathrm{MH}_{3}{ }^{2+}
$$

$$
\begin{gathered}
\left(\begin{array}{l}
K_{1}=\frac{K_{\mathrm{b}_{1}}}{K_{\mathrm{w}}}=10^{5} \mathrm{~mol}^{-1} l^{4}, \\
K_{2}=\frac{K_{\mathrm{b}_{2}}}{K_{\mathrm{w}}}=1 \mathrm{~mol}^{-1} l^{6}\left(25^{\circ} \mathrm{C}\right), \\
K_{\mathrm{w}}=10^{-14} \mathrm{~mol}^{2} l^{-2}\left(25^{\circ} \mathrm{C}\right)
\end{array}\right) \\
\mathrm{HCHO}+\mathrm{H}^{+} \stackrel{K_{3}}{\leftrightarrows} \stackrel{+}{\mathrm{C}} \mathrm{H}_{2} \mathrm{OH} \\
\left(K_{3}=\frac{K_{\mathrm{b}}}{K_{\mathrm{w}}}=1.62 \times 10^{-6} \mathrm{~mol}^{-1} l\left(23^{\circ} \mathrm{C}\right)^{5}\right)
\end{gathered}
$$

Thus, the rate law would be expressed generally by eq 3 , then transformed to eq 4 , and then derived to eq 5 because of "ambiguities in kinetics"; in eq $3, a_{1}, a_{2}, b$, and $c$ are such constants as those

$$
\begin{aligned}
\text { rate }= & c\left([\mathrm{MH}]+a_{1}\left[\mathrm{MH}_{2}^{+}\right]+a_{2}\left[\mathrm{MH}_{3}{ }^{2+}\right]\right) \\
& \times\left([\mathrm{HCHO}]+b\left[\stackrel{+}{\mathrm{C}}{ }_{2} \mathrm{OH}\right]\right) \\
= & k_{1}[\mathrm{MH}][\mathrm{HCHO}]+k_{2}[\mathrm{MH}]\left[\stackrel{+}{\mathrm{C}} \mathrm{H}_{2} \mathrm{OH}\right]
\end{aligned}
$$

$$
\begin{aligned}
& +k_{3}\left[\mathrm{MH}_{2}^{+}\right][\mathrm{HCHO}]+k_{4}\left[\mathrm{MH}_{2}{ }^{+}\right]\left[\stackrel{+}{\mathrm{C}} \mathrm{H}_{2} \mathrm{OH}\right] \\
& +k_{5}\left[\mathrm{MH}_{3}{ }^{2+}\right][\mathrm{HCHO}] \\
& +k_{6}\left[\mathrm{MH}_{3}{ }^{2+}\right]\left[\stackrel{+}{\mathrm{C}} \mathrm{H}_{2} \mathrm{OH}\right]
\end{aligned}
$$

in the kinetic study of the reaction of acetone with iodine. ${ }^{7}$

$$
\begin{aligned}
\text { rate }= & k_{1}[\mathrm{MH}][\mathrm{HCHO}]+k_{3}{ }^{\prime}\left[\mathrm{MH}_{2}{ }^{+}\right][\mathrm{HCHO}] \\
& +k_{4}{ }^{\prime}\left[\mathrm{MH}_{2}{ }^{+}\right]\left[\stackrel{+}{\mathrm{C}} \mathrm{H}_{2} \mathrm{OH}\right] \\
& +k_{6}\left[\mathrm{MH}_{3}{ }^{2+}\right]\left[\stackrel{+}{\mathrm{C}} \mathrm{H}_{2} \mathrm{OH}\right] \\
& \left(k_{3}{ }^{\prime}=\frac{K_{3}}{K_{1}} k_{2}+k_{3}, \quad k_{4}{ }^{\prime}=k_{4}+\frac{K_{2}}{K_{3}} k_{5}\right)
\end{aligned}
$$

A preceding paper stated that the main reaction of the hydroxymethylation in the strongly acid region of $S \doteqdot 1.3 \sim 5.0(\mathrm{pH} 1.7-0.6)$ is a $k_{4}{ }^{\prime}$-reaction ${ }^{1}$ of eq 5 , and that the main reaction in the region of $S \doteqdot 1.02 \sim 1.2(\mathrm{pH}, c a .2 .9-2.0)$, where the rate $v s . \mathrm{pH}$ profile shows the minimum rate, would be a $k_{3}{ }^{\prime}$-reaction. ${ }^{1,2}$ For the above reason, in the region of $0 \leqq S<1.0$ examined in the present work, $k_{4}{ }^{\prime}$ - and $k_{6}$-reactions are clearly of insignificant magnitude, so that eq 5 can be approximately derived to eq 6 .

$$
\text { rate } \doteqdot k_{1}[\mathrm{MH}][\mathrm{HCHO}]+k_{3}{ }^{\prime}\left[\mathrm{MH}_{2}{ }^{+}\right][\mathrm{HCHO}]
$$

As pointed out in the introduction, it is not appropriate that the reaction in the region of $0 \leqq S<1.0$ is assumed to proceed only by the $k_{1}$-reaction proposed by Okano and Ogata, ${ }^{2}$ i.e., the first term on the right-hand side of eq 6 . Next, let us assume that hydroxymethylation is the parallel reaction to the $k_{1}$ - and $k_{3}{ }^{\prime}$-reactions, ${ }^{8}$ i.e., the first and second terms on the right-hand side of eq 6. When hydrochloric acid is added to a mixture of melamine and formaldehyde, the concentration of $\mathrm{MH}_{2}^{+}$at $S=1 / 2$ would be one-half of that of $\mathrm{MH}_{2}{ }^{+}$at $S=1$. Consequently, the size of the $k_{3}{ }^{\prime}$-reaction at $S=1 / 2$ would be one-half of that of the $k_{3}{ }^{\prime}$-reaction at the minimum rate, and accordingly, the contribution of $k_{3}{ }^{\prime}$-reaction to the rate at $S=1 / 2$ is quite small. Hence, the parallel reaction of the $k_{1}$ and $k_{3}{ }^{\prime}$-reactions is not coincident with the experimental result ${ }^{1}$ that the rate at $S=1 / 2$ is slightly larger than that at $S=0$.

Moreover, the upward curvatures given in Figure 3 mean that $R_{0}$ is dependent on a higher power of [melamine $]_{0}$ than one, and this result 
Hydroxymethylation of Melamine with Formaldehyde

cannot be explained by either of the above two mechanisms reported previously.

\section{Rate Equation}

The decided upward curvature in Figure 3 suggests that the melamine molecule (base species), MH, itself acts as a general base catalyst and its conjugate acid, $\mathrm{MH}_{2}^{+}$, acts as a general acid catalyst for the hydroxymethylation of melamine. In this case, the reaction catalyzed by $\mathrm{MH}_{3}{ }^{2+}$ is neglected, because $K_{2}$ is markedly smaller than $K_{1}$ (eq 1) and the concentration of $\mathrm{MH}_{3}{ }^{2+}$ is remarkably small at the $\mathrm{pH}>3$ values studied in this paper.

$$
\begin{aligned}
& \mathrm{MH}+\mathrm{HCHO} \\
&\left.\right|_{i} k_{i}\left[\mathrm{HA}_{i}\right] \sum_{j} k_{j}\left[\mathrm{~B}_{j}\right] \\
& \text { products } \\
&\left(\begin{array}{rl}
\mathrm{B}: & \mathrm{H}_{2} \mathrm{O} \text { and } \mathrm{MH} \\
\mathrm{HA}: & \mathrm{H}_{2} \mathrm{O}, \mathrm{MH}_{2}^{+}, \text {and } \mathrm{H}^{+}
\end{array}\right) \\
& \text {Scheme } 1 .
\end{aligned}
$$

Accordingly, as is clear from Scheme 1, the over-all kinetic expression would be represented by eq 7 at controlled pH, which becomes eq 8 and then eq 9 for initial stage hydroxymethylation. Comparison between eq 9 and 10 gives eq 11 for $k$, and eq 11 shows that $k$ is given as a sum of zero, first, and second order terms relative to [melamine]. Parameters $\alpha, \beta$, and $\gamma$ of eq 11 are expressed by eq 12, 13, and 14, respectively, where $1+K_{3}$ was taken as 1 since $K_{3} \ll 1$ (eq 2).

$$
\begin{aligned}
& \text { rate }=[\mathrm{MH}][\mathrm{HCHO}] \sum_{i} k_{i}\left[\mathrm{HA}_{i}\right] \sum_{j} k_{j}\left[\mathrm{~B}_{j}\right] \\
& =k_{\mathrm{H}_{2} \mathrm{O}}[\mathrm{MH}][\mathrm{HCHO}]+k_{\mathrm{H}^{+}}\left[\mathrm{MH}_{2}{ }^{+}\right][\mathrm{HCHO}]
\end{aligned}
$$

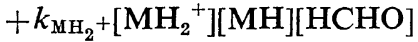

$$
\begin{aligned}
& +k_{\mathrm{MH}}[\mathrm{MH}]^{2}[\mathrm{HCHO}] \\
& +k_{\mathrm{p}}\left[\mathrm{MH}_{2}^{+}\right][\mathrm{MH}]^{2}[\mathrm{HCHO}] \\
& =\left\{\frac{k_{\mathrm{H}_{2} \mathrm{O}}+k_{\mathrm{H}}+K_{1}\left[\mathrm{H}^{+}\right]}{\left(1+K_{1}\left[\mathrm{H}^{+}\right]+K_{1} K_{2}\left[\mathrm{H}^{+}\right]^{2}\right)\left(1+K_{3}\left[\mathrm{H}^{+}\right]\right)}\right. \\
& +\frac{[\mathrm{MH}]_{0}\left(k_{\mathrm{MH}}+k_{\left.\mathrm{MH}_{2}+K_{1}\left[\mathrm{H}^{+}\right]\right)}\right.}{\left(1+K_{1}\left[\mathrm{H}^{+}\right]+K_{1} K_{2}\left[\mathbf{H}^{+}\right]^{2}\right)^{2}\left(1+K_{3}\left[\mathbf{H}^{+}\right]\right)} \\
& \left.+\frac{[\mathrm{MH}]_{0}{ }^{2} k_{\mathrm{p}} K_{1}\left[\mathrm{H}^{+}\right]}{\left(1+K_{1}\left[\mathrm{H}^{+}\right]+K_{1} K_{2}\left[\mathrm{H}^{+}\right]^{2}\right)^{3}\left(1+K_{3}\left[\mathrm{H}^{+}\right]\right)}\right\} \\
& \times[\mathrm{MH}]_{0}[\mathrm{~F}]_{0} \\
& =k[\mathrm{MH}]_{0}[\mathrm{~F}]_{0}
\end{aligned}
$$

$$
\begin{gathered}
k=\alpha+\beta[\mathrm{MH}]_{0}+\gamma[\mathrm{MH}]_{0}{ }^{2} \\
\alpha=\frac{k_{\mathrm{H}_{2} \mathrm{O}}+k_{\mathrm{H}}+K_{1}\left[\mathrm{H}^{+}\right]}{1+K_{1}\left[\mathrm{H}^{+}\right]+K_{1} K_{2}\left[\mathrm{H}^{+}\right]^{2}} \\
\beta=\frac{k_{\mathrm{MH}}+k_{\mathrm{MH}_{2}}+K_{1}\left[\mathrm{H}^{+}\right]}{\left(1+K_{1}\left[\mathrm{H}^{+}\right]+K_{1} K_{2}\left[\mathrm{H}^{+}\right]^{2}\right)^{2}} \\
\gamma=\frac{k_{\mathrm{p}} K_{1}\left[\mathrm{H}^{+}\right]}{\left(1+K_{1}\left[\mathrm{H}^{+}\right]+K_{1} K_{2}\left[\mathrm{H}^{+}\right]^{2}\right)^{3}}
\end{gathered}
$$

\section{Calculation of Rate Constants}

Equation 11, by plotting the relationship between $k$ and [melamine] $]_{0}$, gives an upward curvature with $\alpha$ as an intercept and $\beta+2 \gamma[\mathrm{MH}]_{0}$ as the slope, and gives a straight line with a slope of $\beta$ when $\gamma=0$, i.e., $k_{\mathrm{p}}=0$. Plots of $k$ against [melamine $]_{0}$, using the data in Table $I$, are shown in Figure 4. As a result, a linear dependence was approximately established, and the following values were obtained: $k_{\mathrm{p}} \doteqdot 0$ (The slopes of $1.25-1.45$ in Figure 2 may suggest that $\gamma$ is negligible.); the values of $\alpha$ are $1.72 \times$ $10^{-2}, 1.62 \times 10^{-2}, 1.52 \times 10^{-2}, 1.20 \times 10^{-2}, 0.99 \times$ $10^{-2}$, and $0.91 \times 10^{-2} l \mathrm{~mol}^{-1} \mathrm{~min}^{-1}$, respectively at

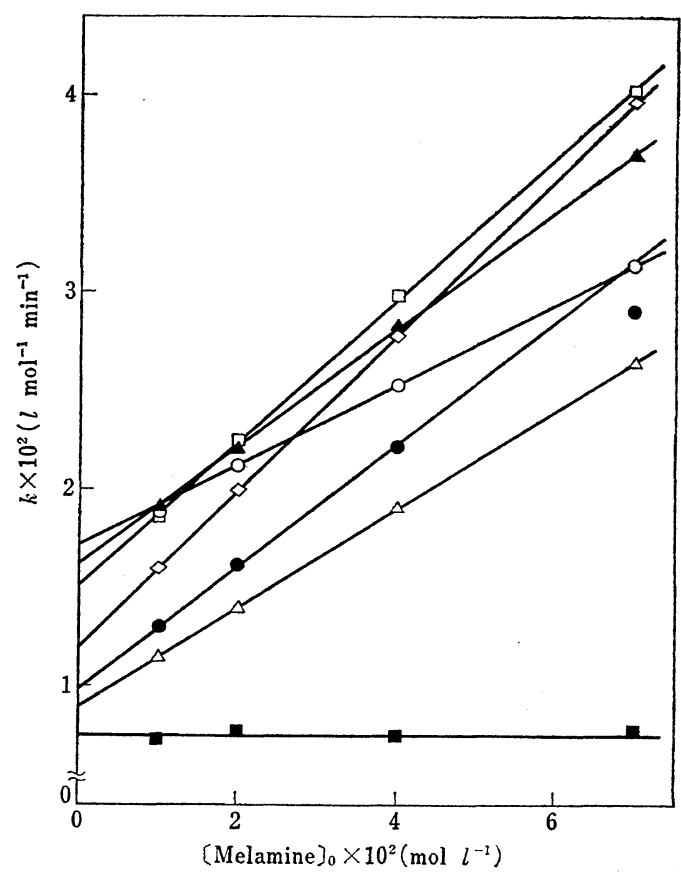

Figure 4. Linear dependence of $k$ on [melamine] at [formaldehyde $]_{0}=0.07 \mathrm{~mol}^{-1}$ and $40^{\circ} \mathrm{C}: \bigcirc, 0$; $\triangle, 0.10 ; \square, 0.25 ; \diamond, 0.50 ; \bigcirc, 0.70 ; \triangle, 0.80 ;$ 1.0 for $S$. 


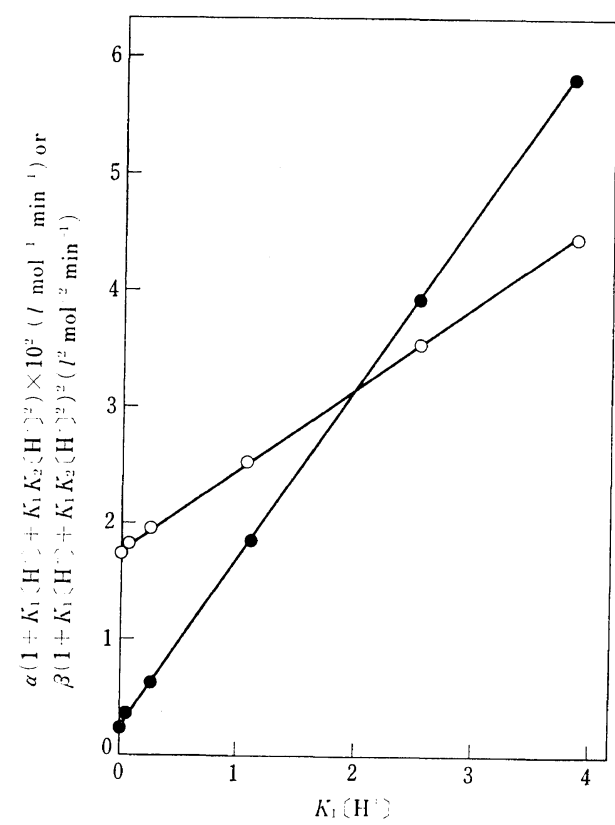

Figure 5. Linear dependence of $\alpha\left(1+K_{1}\left[\mathrm{H}^{+}\right]+\right.$ $\left.K_{1} K_{2}\left[\mathrm{H}^{+}\right]^{2}\right)$ or $\beta\left(1+K_{1}\left[\mathrm{H}^{+}\right]+K_{1} K_{2}\left[\mathrm{H}^{+}\right]^{2}\right)$ on $K_{1}\left[\mathrm{H}^{+}\right]$: $\bigcirc, \alpha\left(1+K_{1}\left[\mathrm{H}^{+}\right]+K_{1} K_{2}\left[\mathrm{H}^{+}\right]^{2}\right) \times 10^{2} ; \mathrm{O}, \beta\left(1+K_{1}\left[\mathrm{H}^{+}\right]+\right.$ $\left.K_{1} K_{2}\left[\mathrm{H}^{+}\right]^{2}\right)^{2}$.

Table II. A tabulation of rate constants at $40^{\circ} \mathrm{C}$ determined in this study

\begin{tabular}{ll}
$k_{\mathrm{H}_{2}} \mathrm{O}, l \mathrm{~mol}^{-1} \mathrm{~min}^{-1}$ & $1.72 \times 10^{-2}$ \\
$k_{\mathrm{H}}+, l \mathrm{~mol}^{-1} \mathrm{~min}^{-1}$ & $6.97 \times 10^{-3}$ \\
$k_{\mathrm{MH}}, l^{2} \mathrm{~mol}^{-2} \mathrm{~min}^{-1}$ & 0.20 \\
$k_{\mathrm{MH}_{2}}+l^{2} \mathrm{~mol}^{-2} \mathrm{~min}^{-1}$ & 1.45 \\
\hline
\end{tabular}

$S=0,0.10,0.25,0.50,0.70$, and 0.80 ; and the corresponding $\beta$ values are $0.20,0.30,0.36,0.40$, 0.31 , and $0.25 l^{2} \mathrm{~mol}^{-2} \mathrm{~min}^{-1}$.

As is anticipated from eq 12, the plots of $\alpha$ $\left(1+K_{1}\left[\mathrm{H}^{+}\right]+K_{1} K_{2}\left[\mathrm{H}^{+}\right]^{2}\right)$ against $K_{1}\left[\mathrm{H}^{+}\right]$give a straight line with an intercept $=k_{\mathrm{H}_{2} \mathrm{O}}$ and a slope $=k_{\mathrm{H}}+$. Figure 5 shows the plots obtained by the substitution of the above values of $\alpha$ and the values of $K_{1}$ and $K_{2}$ of eq 1 into eq 12, where $\left[\mathrm{H}^{+}\right]$is computed from the $\mathrm{pH}$ shown in Table I; the plots indicate a good linearity, and the values of the second-order rate constants of $k_{\mathrm{H}_{2} \mathrm{O}}$ and $k_{\mathrm{H}}+$ are presented in Table II.

From eq 13, the plotting of $\beta\left(1+K_{1}\left[\mathrm{H}^{+}\right]+\right.$ $\left.K_{1} K_{2}\left[\mathrm{H}^{+}\right]^{2}\right)^{2}$ and $K_{1}\left[\mathrm{H}^{+}\right]$is expected to give a straight line with an intercept $=k_{\mathrm{MH}}$ and a slope $=$
$k_{\mathrm{MH}_{2}}+$. Figure 5 shows the plots obtained by substitution of the above values of $\beta$ and the values of $K_{1}$ and $K_{2}$ into eq 13. A linear dependence was observed and the values of the third-order rate constant, $k_{\mathrm{MH}_{2}}+$, and $k_{\mathrm{MH}}$ are listed in Table II.

Since $k_{\mathrm{p}} \doteqdot 0$ as mentioned above, eq 8 can be simplified to eq 15 in the region of $0 \leqq S<1.0$; viz., the rate in the region of $0 \leqq S<1.0$ was found to be dependent on $[\mathrm{MH}]$ and $\left[\mathrm{MH}_{2}^{+}\right]$ in the manner given by eq 15 .

$$
\begin{aligned}
\text { rate }= & k_{\mathrm{H}_{2} \mathrm{O}}[\mathrm{MH}][\mathrm{HCHO}]+k_{\mathrm{H}}+\left[\mathrm{MH}_{2}{ }^{+}\right][\mathrm{HCHO}] \\
& +k_{\mathrm{MH}_{2}}+\left[\mathrm{MH}_{2}{ }^{+}\right][\mathrm{MH}][\mathrm{HCHO}] \\
& +k_{\mathrm{MH}}[\mathrm{MH}]^{2}[\mathrm{HCHO}]
\end{aligned}
$$

In particular, the rate at $S=0$ is speculated to be representable by eq 16 , because $\left[\mathrm{MH}_{2}^{+}\right] \doteqdot 0$ at $S=0$ and both $k_{\mathrm{H}^{+}-}$and $k_{\mathrm{MH}_{2}+\text {-reactions of eq }}$ 15 may be less probable. (This speculation is demonstrated in the following section.)

$$
\text { rate }=k_{\mathrm{H}_{2} \mathrm{O}}[\mathrm{MH}][\mathrm{HCHO}]+k_{\mathrm{MH}}[\mathrm{MH}]^{2}[\mathrm{HCHO}]
$$

Comparison between Observed Profiles ( $k$ vs. $p H$ and $\log k v s . p H)$ and Corresponding Calculated Profiles, and Their Dependence on [Melamine $]_{0}$ As indicated above, hydroxymethylation in the region of $0 \leqq S<1.0$ is a parallel reaction to the $k_{\mathrm{H}_{2} \mathrm{O}^{-}}, k_{\mathrm{H}^{+-}}, k_{\mathrm{MH}_{2}+-}$, and $k_{\mathrm{MH}^{-}}$-reactions, so that the use of parameters $A, B, C$, and $D$ shown in each portion of eq 18 gives eq 17 for $k$.

$$
\begin{gathered}
k=A+B+C+D \\
A=\frac{k_{\mathrm{H}_{2} \mathrm{O}}}{1+K_{1}\left[\mathrm{H}^{+}\right]+K_{1} K_{2}\left[\mathrm{H}^{+}\right]^{2}} \\
B=\frac{k_{\mathrm{H}}+K_{1}\left[\mathrm{H}^{+}\right]}{1+K_{1}\left[\mathrm{H}^{+}\right]+K_{1} K_{2}\left[\mathrm{H}^{+}\right]^{2}} \\
C=\frac{k_{\mathrm{MH}_{2}}+K_{1}\left[\mathrm{H}^{+}\right][\mathrm{MH}]_{0}}{\left(1+K_{1}\left[\mathrm{H}^{+}\right]+K_{1} K_{2}\left[\mathrm{H}^{+}\right]^{2}\right)^{2}} \\
D=\frac{k_{\mathrm{MH}}[\mathrm{MH}]_{0}}{\left(1+K_{1}\left[\mathrm{H}^{+}\right]+K_{1} K_{2}\left[\mathrm{H}^{+}\right]^{2}\right)^{2}}
\end{gathered}
$$

As is clear from eq $18-1$ to $18-4, A, B, C$, and $D$ show the dependence of $k_{\mathrm{H}_{2} \mathrm{O}^{-}}, k_{\mathrm{H}^{+-}}$, $k_{\mathrm{MH}_{2}+-}$, and $k_{\mathrm{MH}^{-}}$reactions on $\left[\mathrm{H}^{+}\right]$and [melamine $]_{0}$, respectively. Substitution of the values of $K_{1}$ and $K_{2}$ (eq 1) and the rate constants (Table II) into eq $18-1$ to $18-4$ gives the cal- 

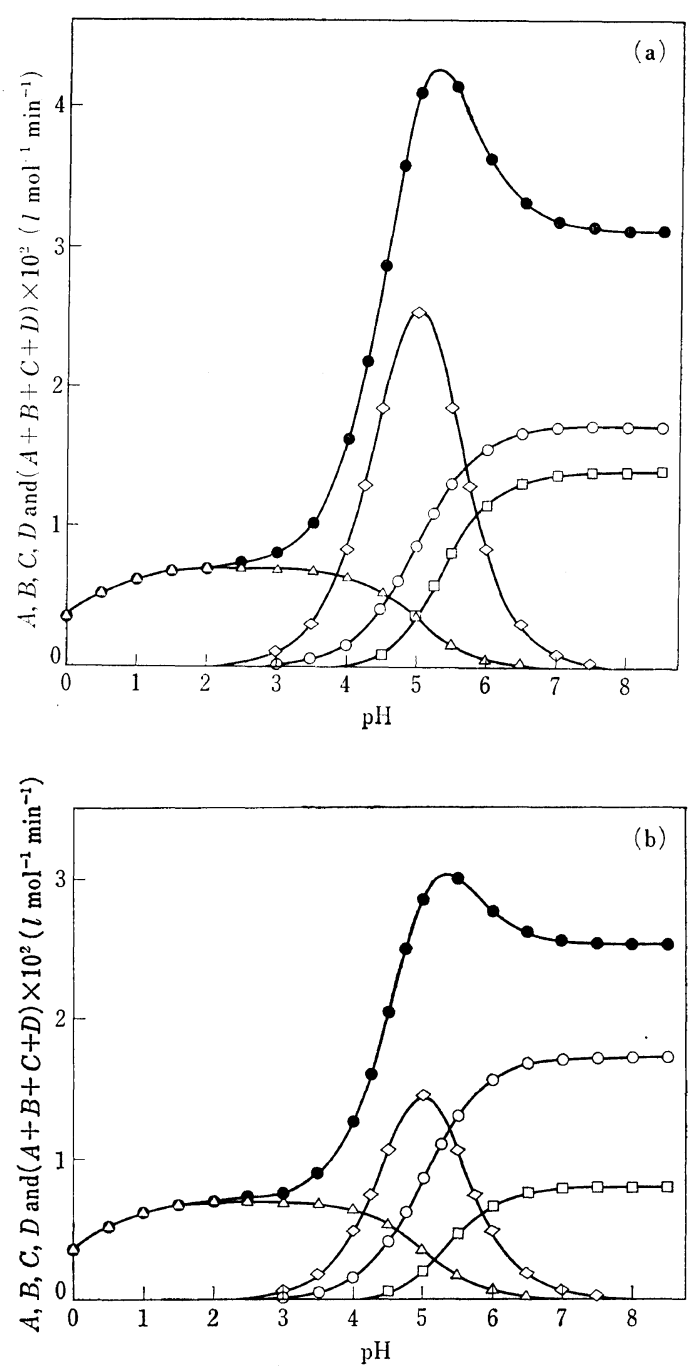

Figure 6. Calculated profiles of $A, B, C, D$, and $(A+B+C+D)$ at $40^{\circ} \mathrm{C}$ as function of $\mathrm{pH}$ and [melamine $]_{0}$ : (a), for [melamine $]_{0}=0.07 \mathrm{~mol} l^{-1} ;(\mathrm{b})$, for [melamine $]_{0}=0.04 \mathrm{~mol} l^{-1} ; \bigcirc, A \times 10^{2} ; \triangle, B \times$ $10^{2} ; \diamond, C \times 10^{2} ; \square, D \times 10^{2} ; \bigcirc,(A+B+C+D) \times 10^{2}$.

culated profiles illustrated in Figure 6, in which (a) and (b) show the calculated profiles of $A, B$, $C, D$ and $(A+B+C+D)$ at [melamine $]_{0}=0.07$ and $0.04 \mathrm{~mol} l^{-1}$, respectively.

As shown by the calculated profiles of Figures 6(a) and (b), $A$ and $D$ are constant in the region from $\mathrm{pH} 8$ to $\mathrm{pH} \mathrm{7,} \mathrm{and} \mathrm{decrease} \mathrm{with} \mathrm{increas-}$ ing acidity in the strongly acid region; $C$ exhibits a striking maximum at $\mathrm{pH}$ 5.0. From $\mathrm{d} C / \mathrm{dpH}=0$, this maximum point is calculated as $\mathrm{pH}=\log K_{1}(=5.0)$ irrespective of [melamine] where $K_{2}$ was taken as zero or, in other words, the $k_{\mathrm{MH}_{2}}+$-reaction attains a maximum rate when the concentration of melamine molecules is equal to that of $\mathrm{MH}_{2}^{+}$(half-neutralization point of melamine); $B$ is constant $(B \doteqdot 0)$ in the region of $\mathrm{pH} 8-7$, and increases with increasing acidity in the more strongly acid region.

Similarly, the calculated profiles of $\log A$, $\log B, \log C, \log D$, and $\log (A+B+C+D)$ at [melamine $]_{0}=0.07 \mathrm{~mol} \mathrm{l}^{-1}$ are shown in Figure 7 , together with their slopes against $\mathrm{pH}$.

Figures $8(a)$ and (b) demonstrate the coincidence of the observed profiles of $k v s . \mathrm{pH}$ and $\log k v s . \mathrm{pH}$ (Table I) with the corresponding calculated profiles in the $\mathrm{pH}$ region of $3-8$. Figure 8 also shows that the observed values of $k$ increase with the increasing of [melamine] at constant $\mathrm{pH}$ and have a maximum at $\mathrm{pH}$, ca. 5.2; these results are in accord with the fact that $A$ and $B$ at a given $\mathrm{pH}$ are constant regardless of [melamine $]_{0}$, whereas $C$ and $D$ at a given $\mathrm{pH}$ increase with the increasing of [melamine $]_{0}$ (eq 18-1 to 18-4 and Figure 6).

However, the calculated profile of Figure 8 is not entirely coincident with the corresponding observed one in the strongly acidic region $(\mathrm{pH}<c a .1 .7)$, since the observed rate in this region increases with increasing acidity (slope, $\mathrm{d} \log k / \mathrm{dpH} \doteqdot-0.7)^{1}$. Hence, this result is com-

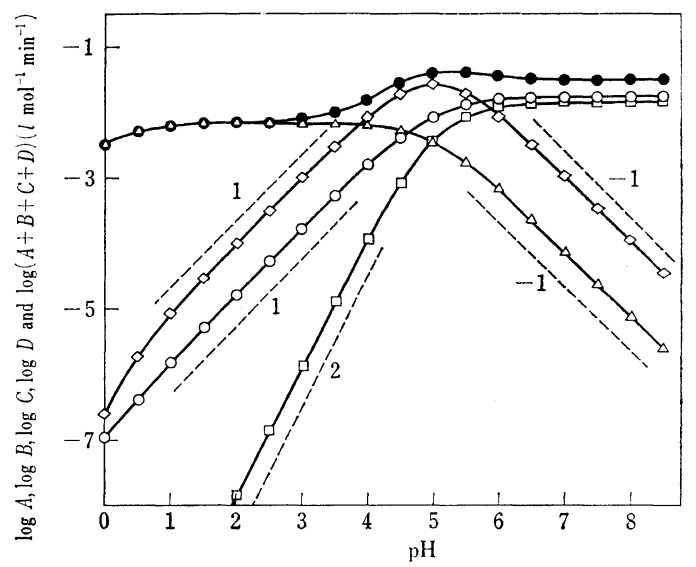

Figure 7. Calculated profiles of $\log A, \log B$, $\log C, \log D$, and $\log (A+B+C+D)$ at [melamine $]_{0}=0.07 \mathrm{moll}^{-1}$ and $40^{\circ} \mathrm{C}$ as function of $\mathrm{pH}$ : $\bigcirc, \log A ; \triangle, \log B ; \diamond, \log C ; \square, \log D ;$ $\log (A+B+C+D)$; dotted line, slope. 

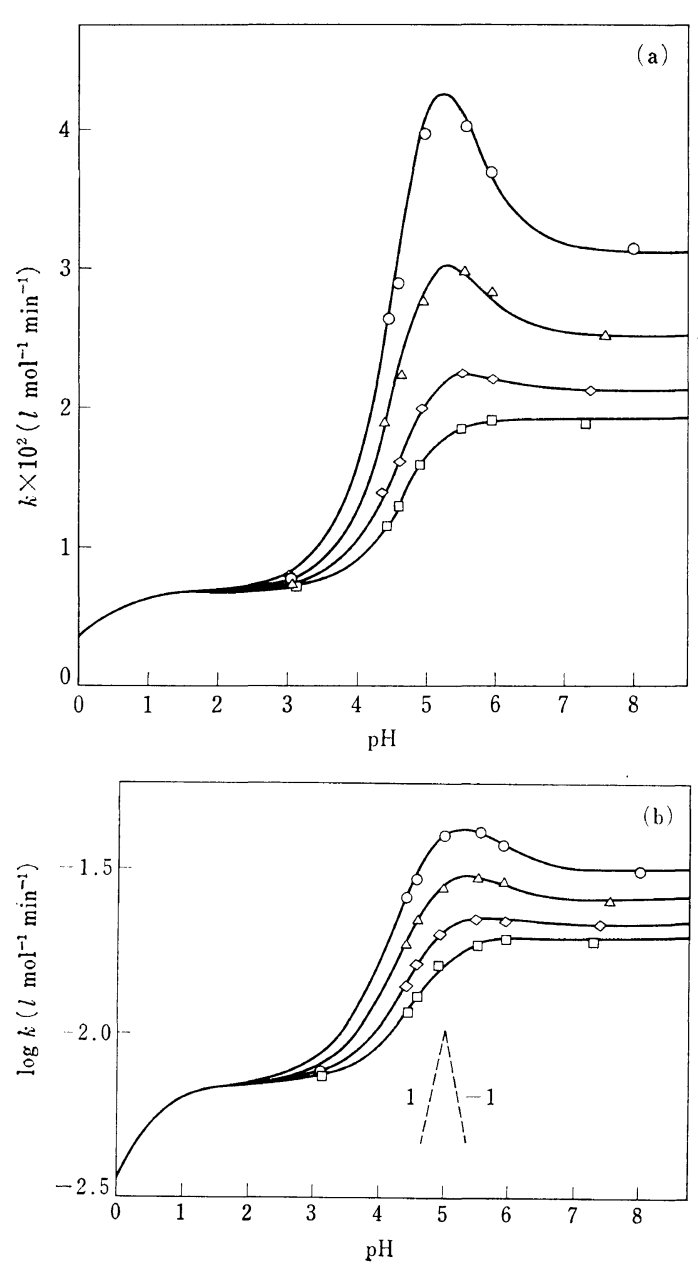

Figure 8. Comparison between observed profiles and corresponding calculated profiles for the hydroxymethylation of melamine at $40^{\circ} \mathrm{C}$ : (a) solid line, calculated profiles of $(A+B+C+D) \times 10^{2}$; (b) solid line, calculated profiles of $\log (A+B+C+D)$. The observed values of $k: \bigcirc, 0.07 \mathrm{~mol} \mathrm{l}^{-1} ; \triangle$, $0.04 \mathrm{~mol} l^{-1} ; \diamond, 0.02 \mathrm{~mol}^{-1} ; \square, 0.01 \mathrm{~mol}^{-1}$ for [melamine] $]_{0}$ dotted line, slope.

patible with the result of the preceding paper ${ }^{1}$ that the main reaction is the $k_{4}{ }^{\prime}$-reaction of eq 5 (the reaction of $\mathrm{MH}_{2}{ }^{+}$with $\stackrel{+}{\mathrm{C}} \mathrm{H}_{2} \mathrm{OH}$ ) and not $k_{\mathrm{H}_{2} \mathrm{O}^{-}}, k_{\mathrm{H}+-}, k_{\mathrm{MH}_{2}+-}$, and $k_{\mathrm{MH}^{-}}$-reactions (eq 15) for this strongly acidic region.

Effect of $p H$ and [Melamine $]_{0}$ on Relative Contributions of $k_{\mathrm{H}_{2} \mathrm{O}^{-}}, k_{\mathrm{H}^{+-}}, k_{\mathrm{MH}_{2}+}$, and $k_{\mathrm{MH}^{-}}$Reactions Equation 19 follows from eq 18 , and $A: B$ : $C: D$ of eq 19 corresponds to the relative con- tribution among $k_{\mathrm{H}_{2} \mathrm{O}}$-reaction, $k_{\mathrm{H}^{+}-\text {reaction, }}$

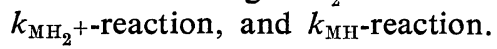

$$
\begin{aligned}
A: B: C: D= & k_{\mathrm{H}_{2} \mathrm{O}}: k_{\mathrm{H}}+K_{1}\left[\mathrm{H}^{+}\right]: \\
& \frac{k_{\mathrm{MH}_{2}+K_{1}\left[\mathrm{H}^{+}\right][\mathrm{MH}]_{0}}}{1+K_{1}\left[\mathrm{H}^{+}\right]+K_{1} K_{2}\left[\mathrm{H}^{+}\right]^{2}}: \\
& \frac{k_{\mathrm{MH}}[\mathrm{MH}]_{0}}{1+K_{1}\left[\mathrm{H}^{+}\right]+K_{1} K_{2}\left[\mathrm{H}^{+}\right]^{2}}
\end{aligned}
$$

As is evident from eq 19 , the relative contributions of these four reactions depend on $\mathrm{pH}$ and [melamine $]_{0}$, so that they are not constant even if $\mathrm{pH}$ is constant. But, the relative contributions of $k_{\mathrm{H}_{2} \mathrm{O}^{-}}$and $k_{\mathrm{H}^{+}}$-reactions and those of $k_{\mathrm{MH}^{-}}$and $k_{\mathrm{MH}_{2}}+$-reactions at controlled $\mathrm{pH}$ are respectively constant, because $A / B=k_{\mathrm{H}_{2}} \mathrm{O} /$ $k_{\mathrm{H}}+K_{1}\left[\mathrm{H}^{+}\right]$and $C / D=k_{\mathrm{MH}_{2}}+K_{1}\left[\mathrm{H}^{+}\right] / k_{\mathrm{MH}}$ (eq 19 ).

At $[\text { melamine }]_{0}=0.07 \mathrm{~mol} l^{-1}$, relative contri-

Table III. Effect of $\mathrm{pH}$ on the relative contributions of $k_{\mathrm{H}_{2} \mathrm{O}^{-}}, k_{\mathrm{H}^{+-}}, k_{\mathrm{MH}_{2}+-}$,

\begin{tabular}{|c|c|c|c|c|}
\hline \multirow[b]{2}{*}{$\mathrm{pH}$} & \multicolumn{4}{|c|}{ Relative contributions, $\%$} \\
\hline & $\begin{array}{c}k_{\mathrm{H}_{2} \mathrm{O}^{-}} \\
\text {reaction }\end{array}$ & $\begin{array}{c}k_{\mathrm{H}^{+-}} \\
\text {reaction }\end{array}$ & $\begin{array}{l}k_{\mathrm{MH}_{2}+-}^{+-} \\
\text {reaction }\end{array}$ & $\begin{array}{c}k_{\mathrm{MH}^{-}} \\
\text {reaction }\end{array}$ \\
\hline 2.50 & 0.7 & 94.9 & 4.3 & 0.0 \\
\hline 3.00 & 2.1 & 85.6 & 12.3 & 0.0 \\
\hline 3.25 & 3.4 & 77.0 & 19.6 & 0.0 \\
\hline 3.50 & 5.1 & 65.6 & 29.2 & 0.1 \\
\hline 3.75 & 7.3 & 52.1 & 40.3 & 0.3 \\
\hline 4.00 & 9.6 & 38.7 & 51.0 & 0.7 \\
\hline 4.25 & 11.9 & 27.1 & 59.5 & 1.5 \\
\hline 4.50 & 14.5 & 18.5 & 64.6 & 2.5 \\
\hline 4.75 & 17.3 & 12.5 & 65.1 & 5.1 \\
\hline 5.00 & 21.1 & 8.5 & 61.9 & 8.6 \\
\hline 5.25 & 25.9 & 5.9 & 54.7 & 13.5 \\
\hline 5.50 & 31.7 & 4.1 & 44.7 & 19.5 \\
\hline 5.75 & 37.8 & 2.7 & 33.5 & 26.0 \\
\hline 6.00 & 43.3 & 1.7 & 23.1 & 31.9 \\
\hline 6.25 & 47.5 & 1.1 & 14.9 & 36.5 \\
\hline 6.50 & 50.5 & 0.6 & 9.1 & 39.7 \\
\hline 6.75 & 52.4 & 0.4 & 5.4 & 41.8 \\
\hline 7.00 & 53.6 & 0.2 & 3.1 & 43.1 \\
\hline 7.25 & 54.3 & 0.1 & 1.8 & 43.8 \\
\hline 7.50 & 54.7 & 0.1 & 1.0 & 44.2 \\
\hline 7.75 & 54.9 & 0.0 & 0.6 & 44.5 \\
\hline 8.00 & 55.0 & 0.0 & 0.3 & 44.6 \\
\hline 8.25 & 55.1 & 0.0 & 0.2 & 44.7 \\
\hline 8.50 & 55.1 & 0.0 & 0.1 & 44.7 \\
\hline 8.75 & 55.2 & 0.0 & 0.1 & 44.8 \\
\hline
\end{tabular}
and $k_{\mathrm{MH}-\text { reactions at [melamine] }}=$ $0.07 \mathrm{~mol} \mathrm{l}^{-1}$ and $40^{\circ} \mathrm{C}$ 
Hydroxymethylation of Melamine with Formaldehyde
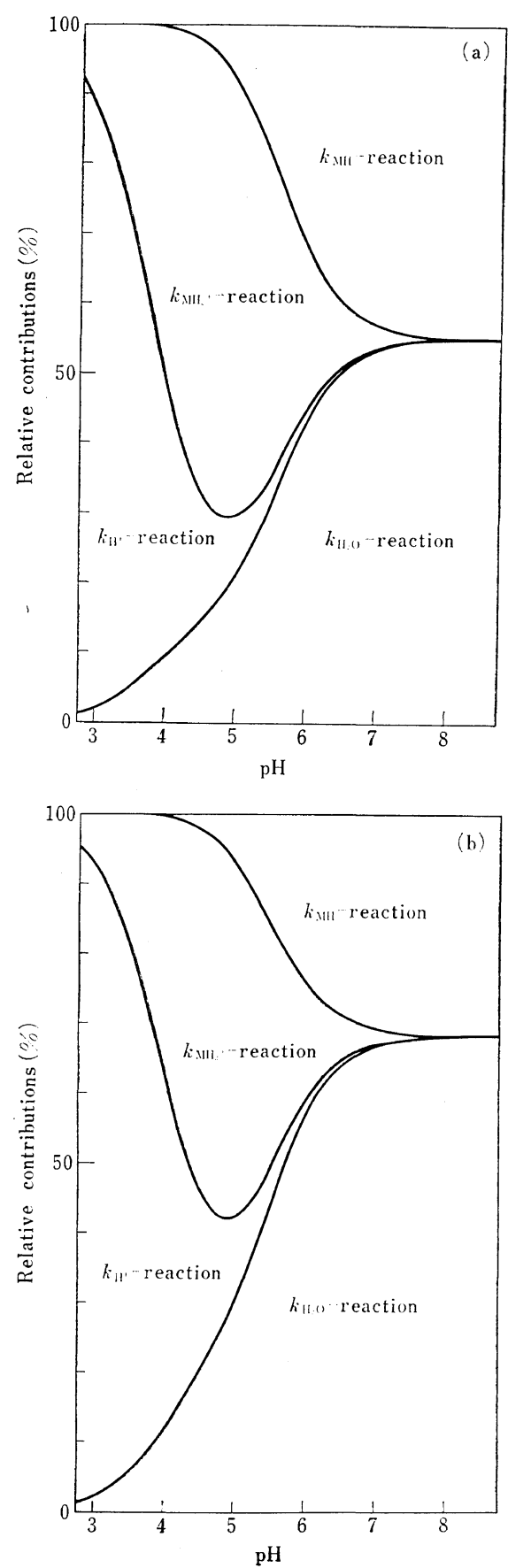

Figure 9. Effect of $\mathrm{pH}$ and [melamine] $]_{0}$ on relative contributions of $k_{\mathrm{H}_{2} \mathrm{O}^{-}, k_{\mathrm{H}}+-,} k_{\mathrm{MH}_{2}}+-$, and $k_{\mathrm{MH}^{-}}$ reactions at $40^{\circ} \mathrm{C}$ according to rate $=k_{\mathrm{H}_{2}} \mathrm{O}[\mathrm{MH}]$ $[\mathrm{HCHO}]+k_{\mathrm{H}}+\left[\mathrm{MH}_{2}+\right][\mathrm{HCHO}]+k_{\mathrm{MH}_{2}}+\left[\mathrm{MH}_{2}{ }^{+}\right][\mathrm{MH}]$ $[\mathrm{HCHO}]+k_{\mathrm{MH}}[\mathrm{MH}]^{2}[\mathrm{HCHO}]:$ (a) for [melamine $]_{0}=$ $0.07 \mathrm{~mol} \mathrm{l}^{-1}$; (b) for [melamine $]_{0}=0.04 \mathrm{~mol} \mathrm{l}^{-1}$. butions of these reactions were calculated by the use of eq 19 and are given in Table III. Moreover, the relative contributions at [melamine $]_{0}=0.07$, and $0.04 \mathrm{~mol}^{-1}$ are shown graphically in Figures 9(a) and (b) in the region of $\mathrm{pH} 3-8$.

First, the region of $0<S<1.0$ would be described as follows. For example, the relative contributions at $S=1 / 2(\mathrm{pH}$ 5.0) and [melamine $]_{0}=0.07 \mathrm{~mol} l^{-1}$ are as follows: $k_{\mathrm{H}_{2} \mathrm{O}}$-reac-

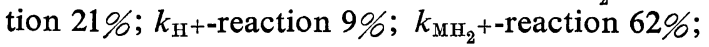
$k_{\mathrm{MH}}$-reaction $9 \%$ (Table III). Consequently, the

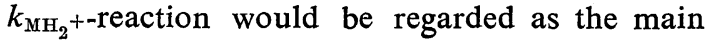
reaction in this case. But, the $k_{\mathrm{H}^{+}-\text {reaction be- }}$ comes the main reaction as the $\mathrm{pH}$ tends toward stronger acidity than $S=1 / 2$, and this result is in agreement with the result of the preceding papers $^{1,2}$ that the main reaction at $S \doteqdot 1.02-1.2$ would be the $k_{\mathrm{H}+\text {-reaction. }}$

Second, the case of $S=0$ would be mentioned. At [melamine $]_{0}=0.07 \mathrm{~mol} \mathrm{l}^{-1}$ and $S=0(\mathrm{pH} 8.0)$, the relative contribution of the $k_{\mathrm{H}_{2} \mathrm{O}}$-reaction is $55 \%$, that of $k_{\mathrm{MH}}$-reaction is $45 \%$, and those of

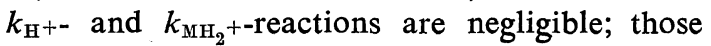
of the latter two reactions are negligible irrespective of [melamine] (Table III and Figures 9(a) and (b)). Therefore, eq 15 at $S=0$ could be reduced by eq 16 , as predicted above.

\section{Reaction Mechanism}

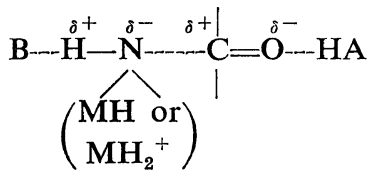

\begin{tabular}{|c|c|c|c|}
\hline Reaction & $\mathrm{H}-\mathrm{N}$ & B & HA \\
\hline$k_{\mathrm{H}_{2} \mathrm{O}}$-reaction & MH & $\mathrm{H}_{2} \mathrm{O}$ & $\mathrm{H}_{2} \mathrm{O}$ \\
\hline$k_{\mathrm{H}+- \text { reaction }}$ & $\mathrm{MH}_{2}^{+}$ & $\mathrm{H}_{2} \mathrm{O}$ & $\mathrm{H}_{2} \mathrm{O}$ \\
\hline \multirow{2}{*}{$k_{\mathrm{MH}_{2}}+$-reaction } & $\mathrm{MH}_{2}^{+}$ & MH & $\mathrm{H}_{2} \mathrm{O}$ \\
\hline & (or $\mathrm{MH}$ & $\mathrm{H}_{2} \mathrm{O}$ & $\mathrm{MH}_{2}^{+}$) \\
\hline$k_{\mathrm{MH}}$-reaction & $\mathrm{MH}$ & MH & $\mathrm{H}_{2} \mathrm{O}$ \\
\hline
\end{tabular}

Scheme 2.

The foregoing kinetic results may be summarized as follows. At $0 \leqq S<1.0$, a complex such as Scheme 2 seems to be formed by a series of the prior equilibrium steps followed by the slow step in which the displacement of the 
leaving $\mathrm{H}$ (proton-transfer) of $\mathrm{H}-\mathrm{N}$ by the electrophile $\mathrm{HCHO}$ is assisted by the general base $B$ and general acid HA catalysis, which may involve concerted mechanisms; the above complex may be analogous to those of the nitrogen bases themselves, ${ }^{9}$ nitrogen bases with the conjugate acids, ${ }^{10}$ and nitrogen bases with carbonyl compounds. ${ }^{9}$

In Scheme 2, the $k_{\mathrm{MH}}$-reaction is the hydroxymethylation of $\mathrm{MH}$ with $\mathrm{HCHO}$ assisted by the general base catalyst $\mathrm{MH}$; on the other hand,

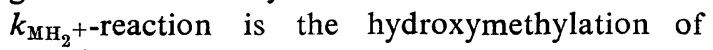
$\mathrm{MH}_{2}{ }^{+}$with $\mathrm{HCHO}$ assisted by the general base catalyst $\mathrm{MH}$, and/or that of $\mathrm{MH}$ with $\mathrm{HCHO}$ assisted by the general acid catalyst $\mathrm{MH}_{2}{ }^{+}$, and these two reaction paths would not be kinetically distinguishable because these have identical rate equations.

At $S=1.0,[\mathrm{MH}]$ is negligible so that hydroxymethylation may mainly proceed through the only remaining one, $\mathrm{MH}_{2}^{+} \cdot \mathrm{HCHO}$ (I) among the complexes of Scheme 2, where the structure ${ }^{4}$ of $\mathrm{MH}_{2}^{+}$has been formulated by the study of UV spectra. It follows from this that the reaction is represented by a more than first-order dependence on [melamine $]_{0}$ at $0 \leqq S<1.0$, whereas it is of an approximately first-order dependence on [melamine] at $S=1.02-1.2$, where the $k_{\mathrm{II}+-}$ reaction would be the main reaction.<smiles>N=C1N=C(N)NC(N)N1</smiles>

(I)

Finally, the reaction mechanism at $S=0$ can be discussed in further detail as follows.

The $\mathrm{pH}$ value increases somewhat $(7.3 \rightarrow 8.0)$ with the increase of [melamine $]_{0}$ at $S=0$, unlike the cases of the other $S$ values (Table I). Therefore, the fact that the reaction-order at $S=0$ is higher than first-order for [melamine $]_{0}$ may be owing to the contribution of the reaction catalyzed by hydroxide ions ( $k_{\mathrm{OH}}$-reaction), because $\left[\mathrm{OH}^{-}\right]=K_{\mathrm{b}_{1}}^{1 / 2}[\mathrm{MH}]^{1 / 2}$ at $S=0$ (from $\mathrm{MH}+$ $\left.\mathrm{H}_{2} \mathrm{O} \stackrel{K_{\mathrm{b}_{1}}}{\leftrightarrows} \mathrm{MH}_{2}^{+}+\mathrm{OH}^{-}\right)$and rate $=k_{\mathrm{OH}^{-}}\left[\mathrm{OH}^{-}\right]$
$[\mathrm{MH}][\mathrm{HCHO}]=k_{\mathrm{OH}}-K_{\mathrm{b}_{1}}^{1 / 2}[\mathrm{MH}]^{3 / 2}[\mathrm{HCHO}] \quad$ (i.e., rate $\propto[\mathrm{MH}]^{3 / 2}$ ) is given for the $k_{\mathrm{OH}-\text {-reaction. }}$ Accordingly, eq 20 is given instead of eq 16 if the $k_{\mathrm{OH}-\text {-reaction also }}$

$$
\begin{aligned}
\text { rate }= & k_{\mathrm{H}_{2} \mathrm{O}}[\mathrm{MH}][\mathrm{HCHO}]+k_{\mathrm{MH}}[\mathrm{MH}]^{2}[\mathrm{HCHO}] \\
& +k_{\mathrm{OH}-}\left[\mathrm{OH}^{-}\right][\mathrm{MH}][\mathrm{HCHO}]
\end{aligned}
$$

participates, and becomes eq 21 at $S=0$.

$$
\begin{aligned}
\text { rate }= & k_{\mathrm{H}_{2} \mathrm{O}}[\mathrm{MH}][\mathrm{HCHO}]+k_{\mathrm{MH}}[\mathrm{MH}]^{2}[\mathrm{HCHO}] \\
& +k_{\mathrm{OH}}-K_{\mathrm{b}_{1}}^{1 / 2}[\mathrm{MH}]^{3 / 2}[\mathrm{HCHO}]
\end{aligned}
$$

At $S=0,[\mathrm{MH}]=[\mathrm{MH}]_{0} /\left(1+K_{1}\left[\mathrm{H}^{+}\right]+K_{1} K_{2}\left[\mathrm{H}^{+}\right]^{2}\right)$ $\doteqdot[\mathrm{MH}]_{0}$ is obtained, and hence eq 21 gives eq 22 for $k$ at $S=0$.

$$
k=k_{\mathrm{H}_{2} \mathrm{O}}+k_{\mathrm{MH}}[\mathrm{MH}]_{0}+k_{\mathrm{OH}}-K_{\mathrm{b}_{1}}^{1 / 2}[\mathrm{MH}]_{0}^{1 / 2}
$$

Equation 22 shows that $k$ is given as a sum of zero, first, and square root order terms for [melamine $]_{0} . \quad$ As is clear from eq 22, plots of $k$ vs. [melamine] $]_{0}$ shows the downward curvature (the slope $=k_{\mathrm{MH}}+(1 / 2) k_{\mathrm{OH}}-K_{\mathrm{b}_{1}}^{1 / 2}[\text { melamine }]_{0}^{-1 / 2}$ ) if

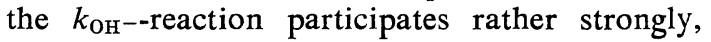
but shows a straight line when the $k_{\mathrm{MH}}$-reaction

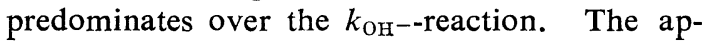
proximate linear dependence of $k$ on [melamine] (Figure 4 ) would suggest that the $k_{\mathrm{OH}^{-}-\text {reaction }}$ is of insignificant magnitude.

In details, plots of $k$ against [melamine] ${ }_{0}^{1 / 2}$ give an upward curvature (the slope $=2 k_{\mathrm{MH}}$ [melamine $]_{0}^{1 / 2}+k_{\mathrm{OH}-K_{\mathrm{b}_{1}}}^{1 / 2}$ ), but give a straight line with the slope of $k_{\mathrm{OH}}-K_{\mathrm{b}_{1}}^{1 / 2}$ if the $k_{\mathrm{OH}-\text {-reaction }}$ were predominates over the $k_{\mathrm{MII}}$-reaction, as eq 22 shows. This speculation may be associated with ammonolysis of methyl phenylacetate and

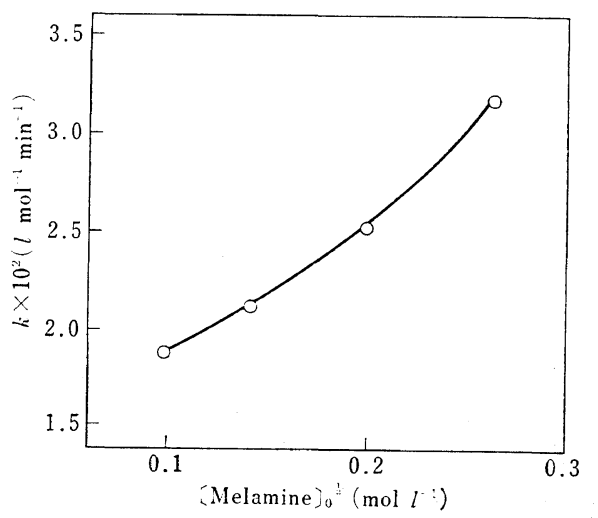

Figure 10. Plots of $k v s$. [melamine $]_{0}^{1 / 2}$ in the absence of catalyst; taken from Run $1-4$ in Table $I$. 
its derivatives with ammonia, ${ }^{11}$ because this reaction follows a more than first-order dependence on [ammonia] and plots of $k v s$. [ammonia $]_{0}^{1 / 2}$ are linear, where $k$ is the second-order rate constant if $R_{0}=k[\text { ester }]_{0}[\text { ammonia }]_{0}$ is assumed. The slight upward curvature between $k$ and [melamine] ${ }_{0}^{1 / 2}$ given in Figure 10 shows that the contribution of the $k_{\mathrm{OH}-\text {-reaction may }}$ be small. Even if the plots in Figure 10 were to be linear within experimental error, the value of $k_{\mathrm{OH}}-\doteqdot 1.89 \times 10^{3} \mathrm{l}^{2} \mathrm{~mol}^{-2} \mathrm{~min}^{-1}$ can be evaluated at $40^{\circ} \mathrm{C}$, since the $k_{\mathrm{OH}^{-}-\text {reaction predom- }}$ inates over $k_{\mathrm{MH}}$-reaction in this case and the slope entails $k_{\mathrm{OH}}-K_{\mathrm{b}_{1}}^{1 / 2}$ as indicated above; but the $k_{\mathrm{OH}^{-}}$value has been reported as $38 l^{2} \mathrm{~mol}^{-2}$ $\min ^{-112}$ at $30^{\circ} \mathrm{C}$ for the hydroxymethylation of melamine with formaldehyde in the presence of sodium hydroxide catalyst. This marked difference for $k_{\mathrm{OH}^{-}}$values may be explicable from the fact that the enhancement of rate with the increase of hydroxide ions due to increase of [melamine] $]_{0}$ is small at $S=0$.

Acknowledgment. The authors are grateful to Prof. J. Furukawa for his helpful discussions, and to Mr. S. Tsujiguchi and K. Yamasaki for their technical assistance in this work.

\section{REFERENCES}

1. K. Sato and Y. Abe, Kobunshi Ronbunshu, 32, 687 (1975).
2. M. Okano and Y. Ogata, J. Am. Chem. Soc., 74, 5728 (1953).

3. e.g., K. Koeda, Kobunshi Kagaku (Chem. High Polymers), 16, 62 (1959); M. Gordon, J. Appl. Polym. Sci., 10, 115 (1966); K. Sato, Bull. Chem. Soc. Jpn., 40, 724 (1967); D. Braun and V. Legradic, Angew. Makromol. Chem., 36, 41 (1974).

4. J. K. Dixon, N. T. Woodberry, and G.W. Costa, J. Am. Chem. Soc., 69, 599 (1947).

5. M. Wadano, C. Trogus, and K. Hess, Ber., 67, 174 (1934).

6. R. C. Hirt and R. G. Schmitt, Spectrochim. Acta, 12, 127 (1958).

7. R. P. Bell and P. Jones, J. Chem. Soc., 88 (1953).

8. K. Sato, Kogyo Kagaku Zasshi (J. Chem. Soc. Jpn. Ind. Chem. Sect.), 72, 1911, 1915 (1969).

9. L. J. Bellamy, "The Infra-Red Spectra of Complex Molecules," John Wiley \& Sons Inc., New York, N.Y., 1962, pp 252-253.

10. I. M. Kolthoff and M. K. Chantooni, Jr., J. Am. Chem. Soc., 85, 2196 (1963); J. F. Coetzee and G. R. Padmanabhan, J. Am. Chem. Soc., 87, 5005 (1965).

11. R. P. Bell and P. Hamett, J. Am. Chem. Soc., 59, 1568 (1937).

12. K. Sato, S. Koiso, and M. Ishihara, Abstracts, SPSJ 21st Annual Meeting on Macromolecules, Tokyo, May 1972, p 323. 